\title{
Serious Cardiovascular Adverse Events Reported with Intravenous Sedatives: A Retrospective Analysis of the MedWatch Adverse Event Reporting System
}

\author{
Matthew S. Duprey ${ }^{1}$ Nada S. Al-Qadheeb ${ }^{2} \cdot$ Nick O'Donnell $^{3} \cdot$ Keith B. Hoffman ${ }^{4}$ - Jonathan Weinstock ${ }^{5}$. \\ Christopher Madias ${ }^{5} \cdot$ Mo Dimbil $^{4} \cdot$ John W. Devlin ${ }^{1,6}$
}

Published online: 9 August 2019

(c) The Author(s) 2019

\begin{abstract}
Background Serious cardiovascular adverse events (SCAEs) associated with intravenous sedatives remain poorly characterized.

Objective The objective of this study was to compare SCAE incidence, types, and mortality between intravenous benzodiazepines (i.e., diazepam, lorazepam, and midazolam), dexmedetomidine, and propofol in the USA over 8 years regardless of the clinical setting where it was administered.

Methods The Food and Drug Administration's MedWatch Adverse Event Reporting System was searched between 2004 and 2011 using the Evidex ${ }^{\circledR}$ platform from Advera Health Analytics, Inc. to identify all reports that included one or more of ten different SCAEs (package insert incidence $\geq 1 \%$ ) and where an intravenous benzodiazepine, dexmedetomidine, or propofol was the primary suspected drug.

Results Among the 2326 Food and Drug Administration's MedWatch Adverse Event Reporting System cases reported, 394 $(16.9 \%)$ were related to a SCAE. The presence of a SCAE (vs. a non-SCAE) is associated with higher mortality ( 34 vs. $8 \%$, $p<0.001$ ). The percentage of cases with one or more SCAE, the case mortality rate (\%), and the incidence of each SCAE (per $10^{6}$ days of sedative exposure), respectively, were benzodiazepines $(14,26,13)$ [diazepam $(13,23,31)$; lorazepam $(15,43$, 14); midazolam $(14,20,11)]$; dexmedetomidine (40, 15, 13); and propofol $(17,39,7)$. Propofol (vs. either a benzodiazepine or dexmedetomidine) was associated with more total SCAEs (268 vs. 126, $p<0.001$ ) but a lower incidence (per $10^{6}$ days of sedative exposure) of SCAE ( 7 vs. 13, $p=0.0001$ ) and cardiac arrest [6.3 (benzodiazepine) vs. 6.7 (dexmedetomidine) vs. 1.4 (propofol), $p<0.0001]$.

Conclusions Serious cardiac adverse events account for nearly one-fifth of intravenous sedative Food and Drug Administration's MedWatch Adverse Event Reporting System reports. These SCAEs appear to be associated with greater mortality than non-cardiac serious adverse events. Serious cardiac events may be more prevalent with either benzodiazepines or dexmedetomidine than propofol.
\end{abstract}

Electronic supplementary material The online version of this article (https://doi.org/10.1007/s40801-019-00161-y) contains supplementary material, which is available to authorized users.

John W. Devlin

j.devlin@neu.edu

Extended author information available on the last page of the article

\section{Key Points}

Serious cardiac adverse events account for nearly onefifth of intravenous sedative Food and Drug Administration's MedWatch Adverse Event Reporting System reports.

These serious cardiac adverse events appear to be associated with greater mortality than non-cardiac serious adverse events.

Serious cardiac events may be more prevalent with either benzodiazepines or dexmedetomidine than propofol. 


\section{Introduction}

Intravenous sedatives are frequently administered during diagnostic procedures, surgical operations, and periods of mechanical ventilatory support to maintain patient comfort and safety [1-7]. Although intravenous sedatives are usually administered by trained clinicians in monitored settings, their use may lead to adverse events that sometimes result in serious morbidity and mortality [8-12]. Adverse reactions affecting the central nervous and respiratory systems are often an extension of the expected sedative pharmacologic effect and usually predictable; adverse events affecting the cardiovascular system, particularly those that are severe and life threatening, are often not expected [13-15].

Package inserts for the intravenous sedatives most frequently administered across both outpatient and inpatient settings [e.g., benzodiazepines (i.e., diazepam, lorazepam, midazolam), dexmedetomidine, and propofol] list a number of potential cardiac adverse effects [16-20]. While it is hypothesized that dexmedetomidine and propofol have a greater frequency of serious cardiovascular adverse events (SCAEs) than benzodiazepines given their wellestablished cardiac effects, much of these safety data are derived from controlled clinical studies where the number of patients exposed to each sedative is relatively small and patients with underlying risk factor(s) for potential cardiac safety concerns might be excluded [21-23]. The number of post-marketing intravenous sedative safety studies are also small [24-27], and thus the types and frequency of SCAE-associated intravenous sedative use in the USA remains poorly characterized. A better understanding of the epidemiology of SCAEs associated with intravenous sedative use is important when prescribing decisions are being formulated and monitoring practices are refined [28-30].

The Food and Drug Administration's MedWatch Adverse Event Reporting System (FAERS) is the world's largest repository of drug-associated adverse events [31]. However, until recently, and like the European Medicine Agency's PharmacoVigilance system, it has not been feasible to manually search for infrequent adverse events that are associated with commonly prescribed medications $[32,33]$. The Evidex ${ }^{\circledR}$ platform from Advera Health Analytics, Inc. is a new searchable FAERS database system that makes analysis across large cohorts of patients feasible [31, 34-36]. The purpose of this observational study was to characterize and compare the incidence and associated mortality of the ten most clinically important SCAEs between intravenous benzodiazepines (including diazepam, lorazepam, and midazolam), dexmedetomodine, and propofol, over an 8-year period in the USA.

\section{Methods}

\subsection{Study Design}

This retrospective cohort study searched the FAERS database over an 8-year period (1 January, 2004-31 December, 2011) to identify all case reports where one or more of the five intravenous sedatives was administered and the patient experienced one or more of the designated SCAEs. The study evaluation period represented a time frame when each of the sedatives were being used in clinical practice; the 8 years of evaluation was felt to represent a robust period to characterize the incidence of SCAEs for each agent. Cases were excluded if one or more of the following existed: (1) age $<18$ years; (2) care was received outside of the USA; (3) the intravenous sedative was not the primary drug suspected to have caused the SCAE; or (4) the SCAE was not linked to the sedative drug in both the "primary" and "all" FAERS database fields. Pediatric patients were excluded from this analysis given their underlying risks for SCAEs may be different than adults. This analysis received expedited approval from the Institutional Review Boards at Northeastern University and Tufts Medical Center given the de-identified nature of the FAERS database.

\subsection{Sedative Agent Choice}

The five intravenous sedatives included in the analysis [benzodiazepines (i.e., diazepam, lorazepam, and midazolam), dexmedetomidine and propofol] each represent agents that have been approved for use for more than a decade and remain frequently administered in the USA. Other intravenous agents with sedative properties were excluded from this analysis if their use was deemed to be rare (e.g., fospropofol) or involved the administration of only a single intravenous dose (e.g., etomidate). Agents with analgesic properties were also excluded (e.g., opioids, ketamine).

\subsection{Serious Cardiac Adverse Event Identification and Coding}

The SCAEs selected for the analysis were identified using a series of deliberate steps. The most recent package insert for each intravenous sedative was reviewed to determine the SCAEs that have been reported in $\geq 1 \%$ of patients exposed to the agent [16-20]. Each of these SCAEs was then coded using the appropriate Medical Dictionary for Regulatory Activities high- and low-level group terms [Table 1 of the Electronic Supplementary Material (ESM)] [37, 38]. Two experienced cardiac electrophysiologists reviewed this populated list of high- and low-level group terms, and through consensus, identified the ten that would be of the greatest clinical significance to patients, regardless of the clinical 
setting where the adverse event occurred. The evaluated SCAEs included cardiac arrest, ventricular arrhythmia, supraventricular arrhythmia, bradyarrhythmia, Brugada ECG pattern, QTc-interval prolongation, myocardial infarction, stroke, cardiac failure, and coronary ischemia.

\subsection{Data Extraction}

The FAERS database was searched using the Evidex ${ }^{\circledR}$ platform (Advera Health Analytics, Inc., Santa Rosa, CA, USA). Duplicate cases (e.g., multiple reports describing the same adverse event in the same patient) were excluded. Each of the FAERS case reports was then manually reviewed, independently and in duplicate, by two trained data extractors, to determine the patient age, the specific SCAE reported, and whether the patient survived the event.

\subsection{Estimation of Annual Serious Cardiac Adverse Event Incidence}

Evaluation of the FAERS system is limited by the fact the number of patients exposed to the particular medication is unknown. However, estimating SCAE incidence between different intravenous sedatives is of value to clinicians when they make sedative prescribing decisions. In an effort to estimate an actual incidence rate for each SCAE, we obtained total milligram (mg) sales for each intravenous sedative (across all vial sizes and manufacturers) in the USA for each of the 8 study years from Quintiles-IMS Health (Danbury, CT, USA). For the purpose of this analysis, we assumed that if a vial of a sedative was sold in the USA in a specific year, its entire contents were administered to only one patient, a common occurrence in practice, and that none of the contents of the vial was discarded. The total annual sales of each intravenous sedative was converted to annual grams sold and for the purpose of all analyses were presented as $\mathrm{g} \times 10^{6}$. Sedative dosing in the outpatient setting varies substantially. To standardize SCAE incidence by usual intravenous sedative dose, we therefore assumed that all intravenous sedatives were administered in an intensive care unit setting as a continuous infusion at a standard dose $[6,7,21,22]$. In the end, through this process, we were able to determine the cumulative incidence of each SCAE per total sedative day over the 8-year evaluation period. In an effort to better contextualize the frequency of each SCAE to clinicians, the incidence of each SCAE per total sedative day was also converted into the number of sedative days necessary to observe one SCAE.

\subsection{Data Analysis}

All analyses considered benzodiazepines as a class and also as three distinct agents. Across the eight evaluation years, age and mortality were compared for each sedative class between FAERS cases with one or more SCAE and FAERS cases with no SCAE. Data were expressed as mean \pm standard deviation or median (interquartile range). Comparison of dichotomous variables across the groups was performed using a three-way Chi-square test (or Fisher's exact test), as appropriate; comparison of two means was performed using the Student's $t$ test. All comparisons were two tailed; a $p$ value of less than 0.05 was considered significant. All tests were performed using IBM SPSS version 21 (Armonk, NY, USA).

\section{Results}

In total, 5716 FAERS reports were submitted for the five intravenous sedative agents between 2004 and 2011.

Among the 2326 reports meeting all inclusion criteria, 394 (16.9\%) included at least one SCAE (Fig. 1). The subgroup of patients who experienced an SCAE (vs. those who experienced a non-SCAE adverse event) were older if they had received dexmedetomidine $(p=0.01)$ or propofol $(p=0.03)$ (Table 1) and more likely to die if administered a benzodiazepine $(p<0.0001)$ or propofol $(p<0.0001)$. Among the three benzodiazepines studied, mortality was higher when a SCAE was reported for lorazepam $(p=0.0001)$ or midazolam $(p=0.01)$ but not with diazepam $(p=0.15)$.

The distribution of cases with an SCAE by intravenous sedative and SCAE type is shown in Table 2 of the ESM.

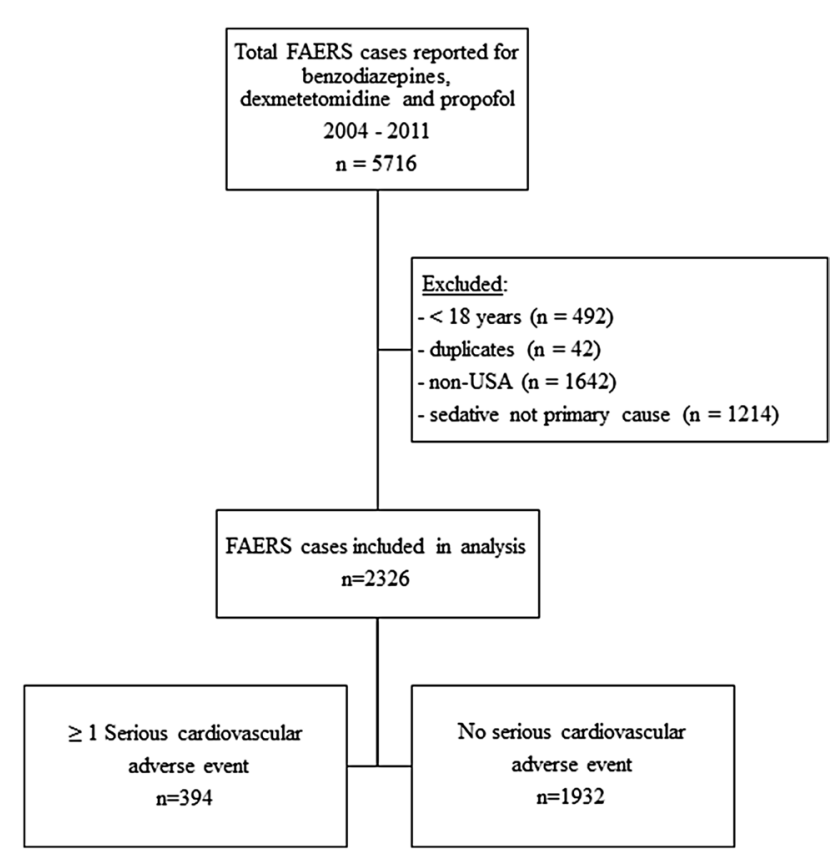

Fig. 1 Flow diagram accounting for all patients included in the final analysis. FAERS Food and Drug Administration's MedWatch Adverse Event Reporting System 
Table 1 Comparison of total number, patient age, and mortality rate between Food and Drug Administration's Adverse Event Reporting System (FAERS) cases with one or more serious cardiovascular event vs. FAERS cases with no serious cardiovascular event for each intravenous sedative over the 8 -year evaluation period

\begin{tabular}{|c|c|c|c|c|c|c|c|c|}
\hline & \multicolumn{2}{|l|}{ FAERS cases } & \multicolumn{3}{|l|}{ Age } & \multicolumn{3}{|l|}{ Mortality } \\
\hline & $\begin{array}{l}\text { Serious } \\
\text { cardiovascular } \\
\text { event } \\
N(\%)\end{array}$ & $\begin{array}{l}\text { No serious } \\
\text { cardiovascular } \\
\text { event } \\
N(\%)\end{array}$ & $\begin{array}{l}\text { Serious } \\
\text { cardiovascular } \\
\text { event (years) }\end{array}$ & $\begin{array}{l}\text { No serious } \\
\text { cardiovascular } \\
\text { event (years) }\end{array}$ & $p$ value & $\begin{array}{l}\text { Serious } \\
\text { cardiovascular } \\
\text { event } \\
N(\%)\end{array}$ & $\begin{array}{l}\text { No serious } \\
\text { cardiovascular } \\
\text { event } \\
N(\%)\end{array}$ & $p$ value \\
\hline $\begin{array}{l}\text { Benzodiazepines } \\
\quad(n=647)\end{array}$ & $93(14)$ & $554(86)$ & 58 & 56 & 0.33 & $24(26)$ & $50(9)$ & $<0.0001$ \\
\hline Diazepam $(n=101)$ & $13(13)$ & $88(87)$ & 53 & 50 & 0.61 & $3(23)$ & $8(9)$ & 0.15 \\
\hline $\begin{array}{l}\text { Lorazepam } \\
\quad(n=138)\end{array}$ & $21(15)$ & $117(85)$ & 52 & 56 & 0.36 & $9(43)$ & $10(9)$ & 0.0001 \\
\hline $\begin{array}{l}\text { Midazolam } \\
\quad(n=408)\end{array}$ & $59(14)$ & $349(86)$ & 62 & 57 & 0.09 & $12(20)$ & $32(9)$ & 0.01 \\
\hline $\begin{array}{l}\text { Dexmedetomidine } \\
\quad(n=83)\end{array}$ & $33(40)$ & $50(60)$ & 63 & 56 & 0.01 & $5(15)$ & $3(6)$ & 0.25 \\
\hline Propofol $(n=1596)$ & $268(17)$ & $1328(83)$ & 52 & 50 & 0.03 & $105(39)$ & $98(7)$ & $<0.0001$ \\
\hline $\begin{array}{l}\text { All sedatives } \\
(n=2326)\end{array}$ & $394(17)$ & $1932(83)$ & 62 & 52 & $<0.01$ & $134(34)$ & $151(8)$ & $<0.0001$ \\
\hline
\end{tabular}

Compared to the benzodiazepines and dexmedetomidine, propofol was associated with the highest number of SCAE cases across all ten SCAE categories. Before adjusting for annual sedative exposure, the number of adverse events differed between the sedative classes for three of the SCAE categories: cardiac arrest, ventricular arrhythmia, and acute cardiac failure. The number of reports of cardiac arrest and cardiac failure were highest with dexmedetomidine; reports of ventricular arrhythmia were highest with propofol.

Total annual US sales for each intravenous sedative are found in Table 3 of the ESM. When adjusted for actual annual sedative use, the incidence rate for nine of the ten SCAEs was greater with both the benzodiazepines and dexmedetomidine than for propofol (Table 2). For the remaining SCAE, cardiac failure, dexmedetomidine was associated with a greater incidence than either the benzodiazepines or propofol. Within the benzodiazepine group, diazepam was associated with more SCAEs, in particular cardiac arrest, than lorazepam or midazolam. When converted to the number of million sedative days administered for a single SCAE to occur, at least 700,000 days of lorazepam, midazolam, dexmedetomidine, or propofol exposure had to occur for a patient to experience one SCAE. For diazepam, one SCAE would occur for every 320,000 days of diazepam use (Table 3).

\section{Discussion}

This article is the first time that the Evidex ${ }^{\circledR}$ platform has been used to identify rare adverse events among patients administered commonly used anesthesiology/critical care medications. Our careful evaluation of the FAERS database shows that the cardiovascular safety of benzodiazepines, dexmedetomidine and propofol is favorable. However, when an SCAE does occur, mortality is increased. At first glance, one might conclude that the cardiovascular risk profile of propofol is worse than that of the benzodiazepines or dexmedetomidine. However, when the much larger annual use of propofol is considered, the incidence of SCAEs with propofol is actually significantly lower.

Among the more than 200,000 Americans who develop an in-hospital cardiac arrest each year, only one-quarter survive [39, 40]. Propofol has been postulated to cause cardiac arrest through its ability to induce cardiovascular failure and subsequent hyperkalemia $[41,42]$. The mechanism by which dexmedetomidine causes cardiac arrest is primarily felt to be related to its propensity to cause bradycardia [43]. Both parenteral diazepam and lorazepam are formulated with propylene glycol - an excipient known to cause lactic acidosis and cardiac arrest when administered in high doses [44, 45]. It is unclear why the risk of cardiac arrest with diazepam was more than three-times greater than that of lorazepam and the risk between lorazepam and midazolam (an agent without propylene glycol) was similar [8, 46, 47]. The lack of information regarding sedative dosing in the FAERS database prevents firm conclusions regarding propylene glycol toxicity from being made. Serum osmolality should be monitored in patients receiving high-dose continuous infusions of diazepam or lorazepam [44, 45]. The five-times greater incidence of cardiac arrest we report both with benzodiazepines (across all agents) and dexmedetomidine (compared to propofol) is noteworthy given that many clinicians might 
Table 2 Comparison of serious cardiac adverse event (SCAE) incidence based on total sedative days over the 8-year study period between sedative groups

\begin{tabular}{|c|c|c|c|c|c|c|c|}
\hline & \multicolumn{4}{|c|}{ Benzodiazepines } & \multirow{2}{*}{$\begin{array}{l}\text { Dexmedeto- } \\
\text { midine }\end{array}$} & \multirow{2}{*}{ Propofol } & \multirow{2}{*}{$p$ value } \\
\hline & All & Diazepam & Lorazepam & Midazolam & & & \\
\hline 1. Cardiac arrest & 6.3 & 21.6 & 6.6 & 5.0 & 6.7 & 1.4 & $<0.0001$ \\
\hline 2. Ventricular arrhythmia & 2.2 & 2.4 & 1.3 & 2.4 & 1.2 & 1.4 & 0.17 \\
\hline 3. Supraventricular arrhythmia & 0.7 & 4.8 & 0.7 & 0.4 & 0.4 & 0.1 & 0.11 \\
\hline 4. Bradyarrhythmia & 1.0 & 0 & 2.0 & 0.7 & 0.8 & 0.6 & 0.61 \\
\hline 5. Brugada ECG pattern & 0 & 0 & 0 & 0 & 0 & 0.2 & 0.14 \\
\hline 6. QTc-interval prolongation & 0 & 0 & 0 & 0 & 0 & 0 & $>0.99$ \\
\hline 7. Myocardial infarction & 1.0 & 2.4 & 1.3 & 0.7 & 1.2 & 0.4 & 0.14 \\
\hline 8. Stroke & 0 & 0 & 0 & 0 & 0 & 0.2 & 0.14 \\
\hline 9. Cardiac failure & 0.5 & 0 & 0 & 0.7 & 1.6 & 0.4 & 0.005 \\
\hline 10. Possible coronary ischemic event & 1.1 & 0 & 2.0 & 0.9 & 1.2 & 0.3 & 0.06 \\
\hline Total SCAEs & 12.7 & 31.2 & 13.8 & 11.0 & 13.1 & 7.4 & 0.0001 \\
\hline
\end{tabular}

Frequency per 10,000,000 days of sedative exposure

$E C G$ electrocardiogram

Table 3 Comparison of the number of million sedative days required for one serious cardiac adverse event (SCAE) to occur between sedative groups

\begin{tabular}{|c|c|c|c|c|c|c|}
\hline & \multicolumn{4}{|c|}{ Benzodiazepines } & \multirow{2}{*}{$\begin{array}{l}\text { Dexme- } \\
\text { detomi- } \\
\text { dine }\end{array}$} & \multirow[t]{2}{*}{ Propofol } \\
\hline & All & Diazepam & Lorazepam & Midazolam & & \\
\hline 1. Cardiac arrest & 1.6 & 0.5 & 1.5 & 2.0 & 1.5 & 7.1 \\
\hline 2. Ventricular arrhythmia & 4.6 & 4.2 & 7.7 & 4.2 & 8.3 & 7.1 \\
\hline 3. Supraventricular arrhythmia & 14.3 & 2.1 & 14.3 & 25.0 & 25.0 & 100.0 \\
\hline 4. Bradyarrhythmia & 10.0 & 0 & 5.0 & 14.3 & 12.5 & 16.7 \\
\hline 5. Brugada ECG pattern & 0 & 0 & 0 & 0 & 0 & 50.0 \\
\hline 6. QTc-interval prolongation & 0 & 0 & 0 & 0 & 0 & 0 \\
\hline 7. Myocardial infarction & 10.0 & 4.2 & 7.7 & 14.3 & 8.3 & 25.0 \\
\hline 8. Stroke & 0 & 0 & 0 & 0 & 0 & 50.0 \\
\hline 9. Cardiac failure & 20.0 & 0 & 0 & 14.3 & 6.3 & 25.0 \\
\hline 10. Possible coronary ischemic event & 9.1 & 0 & 5.0 & 11.1 & 8.3 & 33.3 \\
\hline Total SCAEs & 0.79 & 0.32 & 0.72 & 0.91 & 0.76 & 1.35 \\
\hline
\end{tabular}

Frequency per 1,000,000 days of sedative exposure. Data computed as 1/incidence of SCAEs (expressed per 1,000,000 sedative days of exposure)

$E C G$ electrocardiogram

perceive propofol to be the sedative most likely to potentiate cardiac arrest.

Ventricular arrhythmias may lead to cardiac arrest and are often associated with patient morbidity and mortality $[40,48,49]$. While ventricular arrhythmias are a well-established safety concern with the use of propofol, and are one of the first signs of the propofol-related infusion syndrome [50-52], dexmedetomidine has been reported to reduce ventricular arrhythmias given the fact that it reduces sympathetic drive and heart rate through its vagomimetic effects [53-55]. However, our analysis showed that the rate of ventricular arrhythmias was similar between these two agents. Among the benzodiazepines, propylene glycol accumulation is usually the culprit when a patient develops ventricular arrhythmias (when other causes have been ruled out); however, the reported incidence of ventricular arrhythmias was similar between midazolam and diazepam and both were twice that of lorazepam $[56,57]$.

With the exception of diazepam, an agent known to cause supraventricular arrhythmias [58, 59], the rate of supraventricular arrhythmia was low and nearly identical between dexmedetomidine and propofol. This finding is consistent with literature reports that each of these agents may help convert patients out of a supraventricular arrhythmia [60, 61]. The similar rate of bradyarrhythmias between the three sedative groups is not surprising given that each has a potential mechanism for slowing the heart rate. Benzodiazepines, when administered at high doses, have AV nodal blocking 
effects through their effects on L-type $\mathrm{Ca}^{2+}$ channels [62, 63]. Dexmedetomidine induces bradycardia through both central $\alpha 2$-receptor activity and vagus enhancement $[55,61$, 64]. Propofol has been known to induce bradycardia $[65,66]$ and AV nodal blockade $[67,68]$ through dose-dependent conduction depression, most commonly at the sinoatrial node. The low number of bradyarrhythmias reported to the FAERS database is likely a result of the fact that clinicians are more likely to report adverse events to the FAERS database than are unanticipated. It is not surprising that a Brugada electrocardiographic pattern, a unique phenomenon involving coved-type ST elevation in the precordial chest leads V1-V3, was only reported with propofol. The Brugada pattern has been linked to propofol-related infusion syndrome given that propofol may induce damage to already fragile cardiac sodium channels $[69,70]$.

\subsection{Limitations}

Our analysis, although following all of the methodological steps used in other large-scale FAERS database studies [31, 34-37, 71-74], has important limitations. Although we only included cases where the intravenous sedative was the primary suspected drug, missing data in many case reports made causality challenging to establish. Data on cardiac history, underlying severity of illness, use of non-sedative medications with known cardiac effects, and the dose and duration of the intravenous sedative administered were not able to be considered given that these data are rarely included in FAERS reports. Clinician reporting rates to the FAERS database can be variable and are influenced by the time an agent has been on the market, by outside events (e.g., "dear doctor" letters), the frequency by which an adverse event is known, and how it may change patient outcome after its occurrence. In 2004, the first year of data collection, dexmedetomidine had been on the US market for only 5 years, whereas propofol and midazolam had been on the US market for more than 20 years. A clinician might be more likely to submit a FAERS report for a patient who died from a cardiac arrest where dexmedetomidine was the primary suspected drug than for a patient who experienced reversible bradycardia with dexmedetomidine use. It is therefore likely that the incidence of SCAEs we report underestimates the true occurrence rate. Critically ill adults are often at increased risk for serious cardiac events such as ventricular tachyarrhythmias and cardiac arrest, regardless of intravenous sedative choice, and therefore FAERS case reporters may have erroneously assigned causality to the intravenous sedative administered. These challenges have been noted by the Advera Health Analytics team in previous publications and are inherent in working with the FAERS database [31, 34-37, 72, 73].
When estimating the incidence of the SCAE for each intravenous sedative, we were forced to make assumptions as neither the reason for intravenous sedative use nor the setting where it was administered was usually documented in the FAERS reports. Realizing that a substantial proportion of intravenous sedative use in the USA is administered in the outpatient setting where patients are generally healthy and low intravenous sedative doses are administered for short durations, we were forced to make the assumption that all intravenous sedative use was administered to critically ill patients where dosing is higher and duration of therapy is far longer. Given that the administered dose is not documented in the FAERS database, we also assumed each intravenous sedative was being administered at a standard continuous infusion when in fact infusion rates often change and intravenous bolus dosing is frequently used. All this said, the primary purpose of this analysis was to evaluate the relative incidence of SCAEs and the adjusted incidence rates presented do not change the crude data presented. New, previously unreported SCAEs may have been missed in our analysis given that we relied on only those SCAEs previously reported in package inserts. Although we relied on experienced cardiac electrophysiologists to guide the selection of SCAEs most important to patient outcome, there may be SCAEs not considered in our analysis that could be of importance to clinicians or patients. Last, the incidence of SCAEs may be different in other regions or countries where intravenous sedative practices and experiences are different and in the period since 2013 when practice guidelines have been published recommending the use of dexmedetomidine or propofol rather than a benzodiazepine in critically ill adults requiring continuous sedation $[75,76]$.

\section{Conclusions}

While sedatives are commonly administered, SCAEs associated with their use appear to be very rare. However, among FAERS case reports related to intravenous sedative use, the proportion that are SCAEs is substantial and when a SCAE occurs mortality is high. While the total number of SCAEs attributable to propofol is higher than that reported with either the benzodiazepines or dexmedetomidine, the actual incidence of SCAEs attributable to propofol is lower. Large-scale observational studies are required to identify true SCAE rates and the factors associated with their occurrence. The possibility for SCAEs should be considered during all intravenous sedative prescribing decisions.

Author Contributions Conception and design: MSD, NSA, KBH, JWD; analysis and interpretation: MSD, NSD, NO, KBH, JM, CM, MD, JWD; drafting the manuscript: MSD, NSD, NO, KBH, JM, CM, $\mathrm{MD}$, JWD. JWD is the guarantor of the paper, taking responsibility for the integrity of the work as a whole, from inception to published article. 


\section{Compliance with Ethical Standards}

Funding This work was supported by departmental funds.

Conflict of interest Matthew S. Duprey and John W. Devlin have received support from the National Heart, Lung and Blood Institute (R01HL111111) to help conduct a randomized controlled trial comparing dexmedetomidine and propofol in mechanically ventilated adults. Nada S. Al-Qadheeb, Nick O'Donnell, Keith B. Hoffman, Jonathan Weinstock, Christopher Madias, and Mo Dimbil have no conflicts of interest that are directly relevant to the content of this article.

Ethics Approval Given the de-identified nature of the FAERS database, this analysis received expedited approval from the Institutional Review Boards at Northeastern University and Tufts Medical Center.

Open Access This article is distributed under the terms of the Creative Commons Attribution-NonCommercial 4.0 International License (http://creativecommons.org/licenses/by-nc/4.0/), which permits any noncommercial use, distribution, and reproduction in any medium, provided you give appropriate credit to the original author(s) and the source, provide a link to the Creative Commons license, and indicate if changes were made.

\section{References}

1. Wunsch H, Kahn JM, Kramer AA, Rubenfeld GD. Use of intravenous infusion sedation among mechanically ventilated patients in the United States. Crit Care Med. 2009;37(12):3031-9.

2. Sims PG, Kates CH, Moyer DJ, Rollert MK, Todd DW. Anesthesia in outpatient facilities. J Oral Maxillofac Surg. 2012;70(11 Suppl. 3): $31-49$.

3. Liu H, Waxman DA, Main R, Mattke S. Utilization of anesthesia services during outpatient endoscopies and colonoscopies and associated spending in 2003-2009. JAMA. 2012;307(11):1178-84.

4. Toman H, Erkilinc A, Kocak T, et al. Sedation for transesophageal echocardiography: comparison of propofol, midazolam and midazolam-alfentanil combination. Med Glas (Zenica). 2016;13(1):18-24.

5. Myers R, Lozenski J, Wyatt M, et al. Sedation and analgesia for dressing change: a survey of American Burn Association burn centers. J Burn Care Res. 2017;38:e48-54.

6. MacLaren R, Sullivan PW. Pharmacoeconomic modeling of lorazepam, midazolam, and propofol for continuous sedation in critically ill patients. Pharmacotherapy. 2005;25(10):1319-28.

7. Barr J, Fraser GL, Puntillo K, et al. Clinical practice guidelines for the management of pain, agitation, and delirium in adult patients in the intensive care unit. Crit Care Med. 2013;41(1):263-306.

8. Devlin JW, Mallow-Corbett S, Riker RR. Adverse drug events associated with the use of analgesics, sedatives, and antipsychotics in the intensive care unit. Crit Care Med. 2010;38(6 Suppl.):S231-43.

9. Riker RR, Fraser GL. Adverse events associated with sedatives, analgesics, and other drugs that provide patient comfort in the intensive care unit. Pharmacotherapy. 2005;25(5 Pt 2):8S-18S.

10. Melloni C. Morbidity and mortality related to anesthesia outside the operating room. Minerva Anestesiol. 2005;71(6):325-34.

11. Bellolio MF, Gilani WI, Barrionuevo P, et al. Incidence of adverse events in adults undergoing procedural sedation in the emergency department: a systematic review and meta-analysis. Acad Emerg Med. 2016;23(2):119-34.
12. Hong KS, Choi EY, Park DA, Park J. Safety and efficacy of the moderate sedation during flexible bronchoscopic procedure: a systematic review and meta-analysis of randomized controlled trials. Medicine (Baltimore). 2015;94(40):e1459.

13. Guo Y, Zhang H, Feng X, Wang A. A retrospective study of risk factors for cardiopulmonary events during propofol-mediated gastrointestinal endoscopy in patients aged over 70 years. Middle East J Anaesthesiol. 2012;21(4):505-11.

14. Hug CC Jr, McLeskey CH, Nahrwold ML, et al. Hemodynamic effects of propofol: data from over 25,000 patients. Anesth Analg. 1993;77(4 Suppl.):S21-9.

15. Darrouj J, Karma L, Arora R. Cardiovascular manifestations of sedatives and analgesics in the critical care unit. Am J Ther. 2009;16(4):339-53.

16. Ativan (lorazepam) injection [package insert]. Eatontown (NJ): West-Ward Pharmaceuticals Corp; 2017. https://dailymed.nlm. nih.gov/dailymed/getFile.cfm?setid=5fc0e987-61c9-40c4-b0d5fcea07c8733e\&type $=$ pdf \&name $=5$ fc0e987-61c9-40c4-b0d5fcea07c8733e. Accessed 09 May 2019.

17. Midazolam injection [package insert]. Lake Forest (IL): Akorn, Inc; 2016. https://dailymed.nlm.nih.gov/dailymed/ getFile.cfm?setid $=737361 \mathrm{a} 0-8 \mathrm{db} 1-4 \mathrm{~d} 3 \mathrm{c}-\mathrm{ba5e}-44 \mathrm{df} 3 \mathrm{f} 49 \mathrm{fa}$ $22 \&$ type $=$ pdf $\&$ name $=737361 \mathrm{a} 0-8 \mathrm{db} 1-4 \mathrm{~d} 3 \mathrm{c}-\mathrm{ba} 5 \mathrm{e}-44 \mathrm{df} 3 \mathrm{f} 49 \mathrm{fa}$ 22. Accessed 09 May 2019.

18. Precedex (dexmedetomidine) injection [package insert]. Lake Forest (IL): Hospira Inc; 2016. https://dailymed.nlm.nih.gov/daily $\mathrm{med} /$ getFile.cfm?setid $=548 \mathrm{a} 88 \mathrm{c} 0$-afda- $427 \mathrm{e}-75 \mathrm{ac}-5 \mathrm{af0}$ cfa222 $4 \mathrm{c} \&$ type $=$ pdf $\&$ name $=548 \mathrm{a} 88 \mathrm{c} 0-\mathrm{afda}-427 \mathrm{e}-75 \mathrm{ac}-5 \mathrm{af0} \mathrm{cfa} 2224 \mathrm{c}$. Accessed 09 May 2019.

19. Diazepam injection [package insert]. Lake Forest (IL): Hospira Inc; 2016. https://dailymed.nlm.nih.gov/dailymed/ getFile.cfm?setid $=41044928$-dd1f-40bf- 1 fa6-709dff5591 $24 \&$ type $=$ pdf $\&$ name $=41044928$-dd1f-40bf-1fa6-709dff559124. Accessed 09 May 2019.

20. Diprivan (propofol) injection [package insert]. Lake Zurich (IL): Fresenius Kabi USA LLC; 2014. https://dailymed.nlm.nih.gov/ dailymed/getFile.cfm?setid=e3105799-a4b6-f3f4-e6e2-b2b29 bbdb538\& type $=$ pdf \&name $=e 3105799-a 4 b 6-f 3 f 4-e 6 e 2-b 2 b 29$ bbdb538. Accessed 09 May 2019.

21. Riker RR, Shehabi Y, Bokesch PM, et al. Dexmedetomidine vs midazolam for sedation of critically ill patients: a randomized trial. JAMA. 2009;301(5):489-99.

22. Pandharipande PP, Pun BT, Herr DL, et al. Effect of sedation with dexmedetomidine vs lorazepam on acute brain dysfunction in mechanically ventilated patients: the MENDS randomized controlled trial. JAMA. 2007;298(22):2644-53.

23. Jakob SM, Ruokonen E, Grounds RM, et al. Dexmedetomidine vs midazolam or propofol for sedation during prolonged mechanical ventilation: two randomized controlled trials. JAMA. 2012;307(11):1151-60.

24. Carrasco G, Molina R, Costa J, Soler JM, Cabre L. Propofol vs midazolam in short-, medium-, and long-term sedation of critically ill patients :a cost-benefit analysis. Chest. 1993;103(2):557-64.

25. Sanchez-Izquierdo-Riera JA, Caballero-Cubedo RE, Perez-Vela JL, Ambros-Checa A, Cantalapiedra-Santiago JA, Alted-Lopez E. Propofol versus midazolam: safety and efficacy for sedating the severe trauma patient. Anesth Analg. 1998;86(6):1219-24.

26. Wehrmann T, Kokabpick S, Lembcke B, Caspary WF, Seifert H. Efficacy and safety of intravenous propofol sedation during routine ERCP: a prospective, controlled study. Gastrointest Endosc. 1999;49(6):677-83.

27. Dasta JF, Kane-Gill SL, Durtschi AJ. Comparing dexmedetomidine prescribing patterns and safety in the naturalistic setting versus published data. Ann Pharmacother. 2004;38(7-8):1130-5. 
28. Jackson DL, Proudfoot CW, Cann KF, Walsh T. A systematic review of the impact of sedation practice in the ICU on resource use, costs and patient safety. Crit Care. 2010;14(2):R59.

29. Becker DE, Haas DA. Recognition and management of complications during moderate and deep sedation. Part 2: cardiovascular considerations. Anesth Prog. 2011;58(3):126-38.

30. Apfelbaum JL, Silverstein JH, Chung FF, et al. Practice guidelines for postanesthetic care: an updated report by the American Society of Anesthesiologists Task Force on Postanesthetic Care. Anesthesiology. 2013;118(2):291-307.

31. Hoffman KB, Dimbil M, Tatonetti NP, Kyle RF. A pharmacovigilance signaling system based on FDA regulatory action and postmarketing adverse event reports. Drug Saf. 2016;39(6):561-75.

32. Fong JJ, Sylvia L, Ruthazer R, Schumaker G, Kcomt M, Devlin JW. Predictors of mortality in patients with suspected propofol infusion syndrome. Crit Care Med. 2008;36(8):2281-7.

33. Hauben M. Application of an empiric Bayesian data mining algorithm to reports of pancreatitis associated with atypical antipsychotics. Pharmacotherapy. 2004;24(9):1122-9.

34. Hoffman KB, Overstreet BM, Doraiswamy PM. Development of a drug safety ePlatform for physicians, pharmacists, and consumers based on post-marketing adverse events. Drugs Ther Stud. 2013;3(1):4

35. Hoffman KB, Kraus C, Dimbil M, Golomb BA. A survey of the FDA's AERS database regarding muscle and tendon adverse events linked to the statin drug class. PLoS One. 2012;7(8):e42866.

36. Hoffman KB, Demakas A, Erdman CB, Dimbil M, Doraiswamy PM. Neuropsychiatric adverse effects of oseltamivir in the FDA Adverse Event Reporting System, 1999-2012. BMJ. 2013;347:f4656.

37. Hoffman KB, Dimbil M, Kyle RF, et al. A drug safety rating system based on postmarketing costs associated with adverse events and patient outcomes. J Manag Care Spec Pharm. 2015;21(12):1134-43.

38. Medical Dictionary for Regulatory Activities. Standardised MedDRA queries. 2014. www.meddra.org/standardised-meddra-queri es. Accessed 09 May 2019.

39. Mozaffarian D, Benjamin EJ, Go AS, et al. Heart disease and stroke statistics: 2015 update: a report from the American Heart Association. Circulation. 2015;131(4):e290-322.

40. Merchant RM, Yang L, Becker LB, et al. Incidence of treated cardiac arrest in hospitalized patients in the United States. Crit Care Med. 2011;39(11):2401-6.

41. Lee JH, Ko YS, Shin HJ, Yi JH, Han SW, Kim HJ. Is there a relationship between hyperkalemia and propofol? Electrolyte Blood Press. 2011;9(1):27-31.

42. Bermudez EA, Chen MH. Cardiac arrest associated with intravenous propofol during transesophageal echocardiography before DC cardioversion. Heart Dis. 2002;4(6):355-7.

43. Bharati S, Pal A, Biswas C, Biswas R. Incidence of cardiac arrest increases with the indiscriminate use of dexmedetomidine: a case series and review of published case reports. Acta Anaesthesiol Taiwan. 2011;49(4):165-7.

44. Horinek EL, Kiser TH, Fish DN, MacLaren R. Propylene glycol accumulation in critically ill patients receiving continuous intravenous lorazepam infusions. Ann Pharmacother. 2009;43(12):1964-71.

45. Arroliga AC, Shehab N, McCarthy K, Gonzales JP. Relationship of continuous infusion lorazepam to serum propylene glycol concentration in critically ill adults. Crit Care Med. 2004:32(8):1709-14.

46. Berger R, Green G, Melnick A. Cardiac arrest caused by oral diazepam intoxication. Clin Pediatr (Phila). 1975;14(9):842-4.

47. Sherman PM. Letter: further comments on cardiac arrest from diazepam. J Oral Surg. 1975;33(2):86.
48. Kazaure HS, Roman SA, Sosa JA. Epidemiology and outcomes of in-hospital cardiopulmonary resuscitation in the United States, 2000-2009. Resuscitation. 2013;84(9):1255-60.

49. Nadkarni VM, Larkin GL, Peberdy MA, et al. First documented rhythm and clinical outcome from in-hospital cardiac arrest among children and adults. JAMA. 2006;295(1):50-7.

50. Douglas RJ, Cadogan M. Cardiac arrhythmia during propofol sedation. Emerg Med Australas. 2008;20(5):437-40.

51. Rewari V, Kaul H. Sustained ventricular tachycardia in long QT syndrome: is propofol the culprit? Anesthesiology. 2003;99(3):764.

52. Roberts RJ, Barletta JF, Fong JJ, et al. Incidence of propofolrelated infusion syndrome in critically ill adults: a prospective, multicenter study. Crit Care. 2009;13(5):R169.

53. Chrysostomou C, Sanchez-de-Toledo J, Wearden P, et al. Perioperative use of dexmedetomidine is associated with decreased incidence of ventricular and supraventricular tachyarrhythmias after congenital cardiac operations. Ann Thorac Surg. 2011;92(3):964-72.

54. Parent BA, Munoz R, Shiderly D, Chrysostomou C. Use of dexmedetomidine in sustained ventricular tachycardia. Anaesth Intensive Care. 2010;38(4):781.

55. Kamibayashi T, Hayashi Y, Mammoto T, Yamatodani A, Sumikawa K, Yoshiya I. Role of the vagus nerve in the antidysrhythmic effect of dexmedetomidine on halothane/epinephrine dysrhythmias in dogs. Anesthesiology. 1995;83(5):992-9.

56. Barrett JS, Hey EB Jr. Ventricular arrhythmias associated with the use of diazepam for cardioversion. JAMA. 1970;214(7):1323-4.

57. Roelofse JA, van der Bijl P. Cardiac dysrhythmias associated with intravenous lorazepam, diazepam, and midazolam during oral surgery. J Oral Maxillofac Surg. 1994;52(3):247-50.

58. Romano MM, Soares MS, Pastore CA, Tornelli MJ, de Oliveira Guare R, Adde CA. A study of effectiveness of midazolam sedation for prevention of myocardial arrhythmias in endosseous implant placement. Clin Oral Implants Res. 2012;23(4):489-95.

59. Kumagai K, Yamanouchi Y, Matsuo K, Tashiro N, Hiroki T, Arakawa K. Antiarrhythmic and proarrhythmic properties of diazepam demonstrated by electrophysiological study in humans. Clin Cardiol. 1991;14(5):397-401.

60. Liu Q, Kong AL, Chen R, et al. Propofol and arrhythmias: two sides of the coin. Acta Pharmacol Sin. 2011;32(6):817-23.

61. Chrysostomou C, Beerman L, Shiderly D, Berry D, Morell VO, Munoz R. Dexmedetomidine: a novel drug for the treatment of atrial and junctional tachyarrhythmias during the perioperative period for congenital cardiac surgery: a preliminary study. Anesth Analg. 2008;107(5):1514-22.

62. Anand K, Kumar M. Benzodiazepine overdose associated atrioventricular block. Anesth Essays Res. 2013;7(3):419-20.

63. Arroyo Plasencia AM, Ballentine LM, Mowry JB, Kao LW. Benzodiazepine-associated atrioventricular block. Am J Ther. 2012;19(1):e48-52.

64. Zhang X, Schmidt U, Wain JC, Bigatello L. Bradycardia leading to asystole during dexmedetomidine infusion in an 18 year-old double-lung transplant recipient. J Clin Anesth. 2010;22(1):45-9.

65. Huang J, Wilson S. Severe bradycardia after propofol induction. AANA J. 2008;76(6):413.

66. Colson P, Barlet H, Roquefeuill B, Eledjam JJ. Mechanism of propofol bradycardia. Anesth Analg. 1988;67(9):906-7.

67. Noh JI, Lee JH, Woo SY, et al. Complete atrioventricular nodal block after propofol administration in an elderly patient undergoing total knee replacement arthroplasty: a case report. Korean J Anesthesiol. 2013;64(4):363-6.

68. Ganansia MF, Francois TP, Ormezzano X, Pinaud ML, Lepage JY. Atrioventricular Mobitz I block during propofol anesthesia for laparoscopic tubal ligation. Anesth Analg. 1989;69(4):524-5. 
69. Riera AR, Uchida AH, Schapachnik E, Dubner S, Filho CF, Ferreira C. Propofol infusion syndrome and Brugada syndrome electrocardiographic phenocopy. Cardiol J. 2010;17(2):130-5.

70. Martorano PP, Barboni E, Buscema G, Di Rienzo A. A novel anaesthetical approach to patients with brugada syndrome in neurosurgery. Case Rep Anesthesiol. 2013;2013:280826.

71. Hoffman KB, Dimbil M, Erdman CB, Tatonetti NP, Overstreet BM. The Weber effect and the United States Food and Drug Administration's Adverse Event Reporting System (FAERS): analysis of sixty-two drugs approved from 2006 to 2010. Drug Saf. 2014;37(4):283-94.

72. Hoffman KB, Demakas A, Erdman CB, Dimbil M. Postapproval adverse events of new and old anticoagulants. BMJ. 2014;348:g1859.
73. Hoffman KB, Demakas AR, Dimbil M, Tatonetti NP, Erdman CB. Stimulated reporting: the impact of US Food and Drug Administration-issued alerts on the adverse event reporting system (FAERS). Drug Saf. 2014;37(11):971-80.

74. Szarfman A, Tonning JM, Doraiswamy PM. Pharmacovigilance in the 21st century: new systematic tools for an old problem. Pharmacotherapy. 2004;24(9):1099-104.

75. Barr J, Fraser GL, Puntillo K, et al. Clinical practice guidelines for the management of pain, agitation, and delirium in adult patients in the intensive care unit. Crit Care Med. 2013;41:263-306.

76. Devlin JW, Skrobik Y, Gelinas C, et al. Clinical practice guidelines for the prevention and management of pain, agitation/sedation, delirium, immobility, and sleep disruption in adult patients in the ICU. Crit Care Med. 2018;46(9):1532-48.

\section{Affiliations}

\section{Matthew S. Duprey ${ }^{1}$ - Nada S. Al-Qadheeb ${ }^{2}$. Nick O'Donnell ${ }^{3} \cdot$ Keith B. Hoffman ${ }^{4}$ - Jonathan Weinstock ${ }^{5}$. Christopher Madias $^{5} \cdot$ Mo Dimbil $^{4} \cdot$ John W. Devlin ${ }^{1,6}$}

1 Northeastern University School of Pharmacy, 360 Huntington Ave, 140 TF R216, Boston, MA 02115, USA

2 Department of Critical Care, Hafer Al Batin Central Hospital, Qurtubah, Hafar Al Batin, Saudi Arabia

3 Albany College of Pharmacy, Albany, NY, USA

4 Advera Health Analytics, Inc., Santa Rosa, CA, USA
5 Division of Cardiology, Tufts Medical Center, Boston, MA, USA

6 Division of Pulmonary, Critical Care and Sleep Medicine, Tufts Medical Center, Boston, MA, USA 